\title{
Tools that assess functional decline: systematic literature review update
}

This article was published in the following Dove Press journal:

Clinical Interventions in Aging

29 April 2013

Number of times this article has been viewed

\author{
Kate Beaton \\ Karen Grimmer \\ International Centre for Allied \\ Health Evidence, University of South \\ Australia, Adelaide, Australia
}

Background: Screening for risk of functional decline in the elderly is increasingly important in ambulatory health care settings, to ensure that appropriate services are provided to reduce the risk of downstream decline. These screening tools should have sound psychometric properties and clinical utility.

Design: An updated systematic literature review for (1) new screening tools published since the last review, conducted in 2007 and published in 2008, and (2) recent research into psychometric properties of the five tools identified in the previous review.

Methods: A comprehensive review of multiple databases using the search terms from the Sutton et al review was conducted. The reference lists of included articles were hand-searched for additional articles, and the literature was evaluated with the appropriate critical appraisal tool. Included screening tools should be designed for, or applicable to, hospital emergency departments.

Results: Two relevant new tools were identified (the Simplified PROFUNCTION index and Brief Risk Identification for Geriatric Health Tool). Six additional papers testing psychometric properties of four of the five previously reported screening tools were also found.

Conclusion: Seven relevant screening tools are available with similar validity and reliability estimates. They consider similar constructs and have convincing evidence of applicability to a range of older populations, or different cultures. Identification of Seniors at Risk, is the most frequently reported screening tool. The wider unanswered question is how, why, and where these functional decline screening tools are used; how valid the findings are on ill, stressed, older people in emergency departments; and how the findings are acted upon in terms of community intervention to slow functional decline.

Keywords: functional decline, older adults, screening and assessment tools

\section{Background}

Systematic literature reviews are a good method of presenting the current evidence to busy clinicians in a condensed summary; however, they need to be regularly updated to ensure access to the latest evidence. The systematic review conducted by Sutton et al published in $2008^{1}$ is the first we know of that reported on screening tools to identify older individuals at risk of functional decline, specific to use in a hospital emergency department.

As the general population increases in age, there is a need for a valid and reliable tool that can quickly and accurately screen for functional decline. Functional decline is a term used to reflect the loss of an individual's ability to independently and safely perform activities of daily living (ADLs) (usually at home, in the community). ${ }^{2,3}$ 
Basic ADLs encompass everyday tasks (bathing, dressing, feeding, continence, transferring, and toileting) ${ }^{2}$ and instrumental ADLs address higher-level tasks (shopping, driving, and banking). ${ }^{3}$ Functional decline has been associated with increased rates of mortality, health service use and institutionalization, and higher health care costs. ${ }^{4-6}$ There is currently no gold standard measure of the attributes or timing of functional decline, as it generally occurs insidiously across a number of domains over time. ${ }^{7}$ Functional decline has been variously described, including loss of independence in ADLs, ${ }^{8-10}$ confusion and loss of morale, increasing frequency of falls and use of polypharmacy, ${ }^{8}$ need for permanent institutionalization or permanent care, increased rates of hospitalization, prolonged hospital stays and/or frequent presentations to emergency departments, ${ }^{6,8-10}$ consumption of higher health care costs, ${ }^{11}$ and avoidable mortality. ${ }^{9,10}$

The aim of the Sutton et al ${ }^{1}$ systematic review was to compare the diagnostic accuracy and clinical utility of the then-available screening tools for functional decline, which could be relevant to older adults presenting to hospital emergency departments for crisis health management. That review identified five tools: the Hospital Admission Risk Profile (HARP), ${ }^{12}$ the Identification of Seniors At Risk (ISAR), ${ }^{13}$ the Triage Risk Screening Tool (TRST), ${ }^{14}$ a tool developed by Inouye et al, ${ }^{6}$ and the Score Hospitalier d'Evaluation du Risque de Perte d'Autonomie (SHERPA). ${ }^{15}$

This systematic review aims to update the information presented by Sutton and colleagues ${ }^{1}$, thus providing clinicians with a synthesis of the most current evidence base for current screening tools for functional decline.

\section{Methods}

\section{Updated search approach}

The previous review ${ }^{1}$ conducted library database searches that sought studies from 1990 to November 2007 and limited to English studies only. The updated systematic review reported in this paper therefore sought studies published from November 2007 to October 2012, limited to English studies only.

\section{Search strategy}

Type of studies

Any peer reviewed article was included if it reported on:

- the development and psychometric testing of a new tool for assessing functional decline in ambulatory older adults;

- functional decline tools tested in emergency departments or suitable for this use;

- subsequent testing of the psychometric properties of the five previously reported functional decline tools;
- the subsequent use of one or more of the five functional decline tools reported on in Sutton et al. ${ }^{1}$

\section{Type of participants}

Study participants must have been $\geq 65$ years old and presented to a hospital for treatment of an acute condition.

\section{Types of exposure}

Screening tools designed specifically to identify older people at risk of functional decline or reduced functional status at time of presentation to hospital were included in the report.

\section{Types of comparator}

Any other screening tool(s) that identified older people at risk of functional decline or reduced functional status were included in the report.

\section{Type of outcomes}

Prediction of change in functional status.

\section{Search terms}

The search terms covered older populations, screening tools to assess mental and physical functional decline and/or loss, loss of quality of life, and care and hospitalization. The full search strategy can be obtained from the authors on request.

\section{Literature sources}

Databases searched were AgeLine, CINAHL, Health Source: Nursing/Academic Edition, PsycARTICLES, Psychology and Behavioral Sciences Collection, PsycINFO, AMED, MEDLINE, EMBASE, Cochrane Library, Wiley Online Library. The reference lists of the included articles were hand searched and any texts potentially matching the inclusion criteria were retrieved.

\section{Study selection}

Potentially relevant studies were imported into EndNote reference manager software (Thomson Reuters, New York, NY, USA) and screened for duplicates. Titles and abstracts were screened for relevance to the review questions, and finally full texts were acquired and screened for adherence to inclusion/exclusion criteria. Any disagreements or uncertainties regarding inclusion were resolved via discussion between the authors.

\section{Critical appraisal}

Relevant articles were critically evaluated using critical appraisal tools appropriate for the study design. The qual- 
ity assessment of diagnostic accuracy studies (QUADAS) critical appraisal tool, ${ }^{16}$ which is a validated tool specifically developed to appraise studies assessing the accuracy of diagnostic tools for systematic reviews, was used to appraise the articles on the development of a new tool (See Table 1 for QUADAS scores). Articles reporting on the tools reviewed by Sutton et al ${ }^{1}$ were appraised using the Critical Appraisal Skills Programme (CASP) critical appraisal tool for cohort studies ${ }^{17}$ (see Table 2 for CASP scores).

\section{Data extraction}

The data was extracted into a custom designed spread sheet based on the information extracted by Sutton et al. ${ }^{1}$

This paper reports two separate sets of data:

- Part one: new tools published since Sutton et al's ${ }^{1} 2008$ report to detect functional decline in elderly patients who present to a hospital.

- Part two: subsequent use of the functional decline screening tools identified by Sutton et al. ${ }^{1}$

\section{Results}

\section{Search findings}

The search returned 601 articles. Eight articles were included in this review (see Figure 1 for the Preferred Reporting Items for Systematic Reviews and Meta-Analyses [PRISMA] diagram of search results).

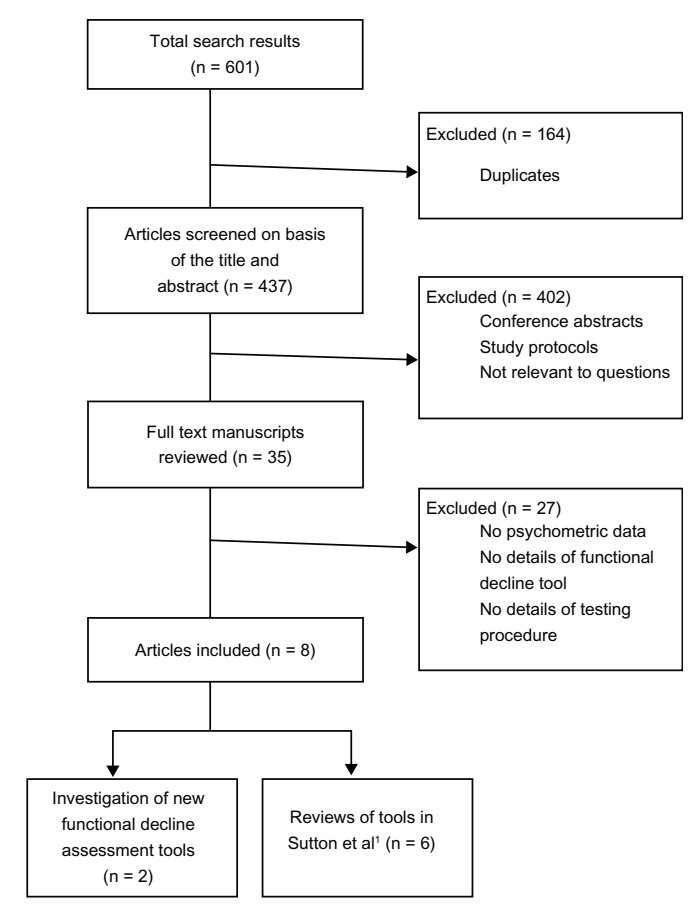

Figure I PRISMA diagram of search results.

Abbreviation: PRISMA, Preferred Reporting Items for Systematic Reviews and Meta-Analyses.

\section{Part one: new tools identified in the search}

Two additional tools to the five identified by Sutton et al ${ }^{1}$ were found:

- Simplified PROFUNCTION index developed by Bernabeu-Wittel et al. ${ }^{18}$

- Brief Risk Identification for Geriatric Health Tool (BRIGHT) developed by Boyd et al. ${ }^{9}$

The Simplified PROFUNCTION index and BRIGHT were assessed using the QUADAS critical appraisal tool. Both screening tools scored moderately for diagnostic accuracy and predictive reliability: the Simplified PROFUNCTION index scored 9/14 and BRIGHT scored 8/14. Both achieved lower scores than those reported for the tools assessed by Sutton et al ${ }^{1}$ (these tools ranging between 10/14 to 12/14 on the QUADAS critical appraisal tool). The psychometric properties and QUADAS scores of the new instruments are outlined in Table 1.

\section{Development of the new tools}

The PROFUNCTION index and the Simplified PROFUNCTION index were developed by Bernabeu-Wittel et a ${ }^{19}$ to assess functional decline in polypathological patients (chronic disease sufferers with multiple pathologies), as the authors believed that the current functional decline assessment tools were not sufficiently specific for this population. The PROFUNCTION index is scored from 0-31 while the Simplified PROFUNCTION index is scored from $0-7$. The Simplified PROFUNCTION index, in which all items have an even weighting, was created in the same manner as the PROFUNCTION index, in which items had unequal weightings, and had minimal prognostic differences amongst the original score items. The Simplified PROFUNCTION index obtained similar goodness of fit and discrimination values as the longer version; as such, Bernabeu-Wittel et al ${ }^{18}$ suggest using the simplified version, as it is easier to perform. In light of this, only the results from the Simplified PROFUNCTION index are reported here. The tool's generalizability is limited to polypathological patients and the tool, to date, has only been tested in one development study in Spain. ${ }^{18}$

The predictive validity of the Simplified PROFUNCTION index ${ }^{18}$ was found to be good when compared to the TRST. ${ }^{14}$ The stability of the final model of the Simplified PROFUNCTION index ${ }^{18}$ was tested with alternate methods (forward and bidirectional selection techniques) to determine whether the resulting model would differ from the original PROFUNCTION index. They found good reliability. The clinical utility of the Simplified PROFUNCTION index was not discussed other than a recommendation to use the simplified version over the original version. 
Table I Psychometric properties of new tools found in this search

\begin{tabular}{|c|c|c|c|c|}
\hline \multirow{2}{*}{$\begin{array}{l}\text { Functional decline } \\
\text { assessment tool }\end{array}$} & \multirow{2}{*}{$\begin{array}{l}\text { Author, date, and } \\
\text { critical appraisal score }\end{array}$} & \multirow{2}{*}{$\begin{array}{l}\text { Population group } \\
\text { and country }\end{array}$} & \multirow{2}{*}{$\begin{array}{l}\text { Reference } \\
\text { standard used }\end{array}$} & \multirow{2}{*}{$\begin{array}{l}\text { Psychometric properties } \\
\text { Content validity }\end{array}$} \\
\hline & & & & \\
\hline $\begin{array}{l}\text { Simplified } \\
\text { PROFUNCTION }\end{array}$ & $\begin{array}{l}\text { Bernabeu-Wittel et al }{ }^{18} \\
\text { QUADAS score: } 9 / 14\end{array}$ & $\begin{array}{l}958 \text { polypathological } \\
\text { patients in } 36 \text { Spanish } \\
\text { hospitals over a } \\
12 \text { month period. } \\
\text { Patients aged } \geq \\
85 \text { years }\end{array}$ & $\begin{array}{l}\text { Flemish version } \\
\text { of TRST }\end{array}$ & $\begin{array}{l}\text { Clinical features (chronic neurological } \\
\text { condition, chronic osteoarticular } \\
\text { disease, class III-IV in New York Heart } \\
\text { Association and/or Medical Research } \\
\text { Council, four or more polypathology } \\
\text { categories), and functional-socio-familial } \\
\text { features (Basal Barthel's Index }<60, \\
\text { risk or established social problem) }\end{array}$ \\
\hline BRIGHT & $\begin{array}{l}\text { Boyd et al }{ }^{9} \\
\text { QUADAS score: } 8 / 14\end{array}$ & $\begin{array}{l}\text { Older peoples } \\
\text { (aged } \geq \\
75 \text { years) presenting } \\
\text { to emergency } \\
\text { departments in } \\
\text { New Zealand }\end{array}$ & $\begin{array}{l}\text { inter-Residential } \\
\text { Assessment } \\
\text { Instrument (interRAl) } \\
\text { Minimum Data Set for } \\
\text { Home Care Version } \\
2.0 \text { (MDS-HC) }\end{array}$ & $\begin{array}{l}\text { I I functional decline measures of need } \\
\text { help with housework; times tripped } \\
\text { or fallen; depression; general health; } \\
\text { shortness of breath with light activity; } \\
\text { need help with bathing; memory } \\
\text { problems; difficulty making decisions, } \\
\text { need help dressing lower body, need } \\
\text { help with transfers, and need help with } \\
\text { personal grooming }\end{array}$ \\
\hline
\end{tabular}

Abbreviations: ADL, activity of daily living; AUC, area under the curve; BRIGHT, Brief Risk Identification for Geriatric Health Tool; Cl, confidence interval; IADL, instrumental ADL; QUADAS, quality assessment of diagnostic accuracy studies; TRST, Triage Risk Screening Tool.

BRIGHT was developed by Boyd et $\mathrm{al}^{9}$ to identify older patients with functional and physical impairments presenting to the emergency department. BRIGHT has a scoring range of $0-11$ (each item is equally weighted) with higher scores negatively correlating to impairment levels. ${ }^{9}$ BRIGHT was compared with the current standard (inter-Residential Assessment Instrument [interRAI] Minimum Data Set for Home Care Version 2.0 [MDS-HC] $)^{19-21}$ as approved by the New Zealand government in functional testing for older adults. There has been no comparison between the BRIGHT instrument and any other functional decline assessment tool. However, as the interRAI tool had not been validated at the time of the Boyd et $\mathrm{al}^{9}$ study, it provided limited validation evidence for the BRIGHT instrument. At this point in time, BRIGHT has only been tested in New Zealand and included Māori and Pasifika elders; however, the cohort reflected predominantly Caucasian participants. ${ }^{9}$ The predictive validity of BRIGHT compared to the New Zealand reference tool was found to be good, when a cut off score of 3-4 is used. Boyd et $\mathrm{al}^{9}$ state that BRIGHT has good reliability, however, they do not report supporting statistical evidence.

BRIGHT was originally designed to be either patient self-administered or administered with the aid of a caregiver; however, Boyd et $\mathrm{al}^{9}$ found that only $25 \%$ of the sample was able to complete the questionnaire without some form of assistance from the research or nursing staff. They did find that BRIGHT requires no special training for health care staff and takes little time to complete. According to Boyd et al, ${ }^{9}$ BRIGHT was designed to be part of a two-stage assessment process; BRIGHT was to be used initially, to quickly identify older adults at risk of functional decline, and then a more intensive tool, in this case the interRAI home care version, used by Boyd et $\mathrm{al}^{9}$ as the validation tool, to establish the level of aid/care that was necessary at the time of discharge and to aid in the design of a home care program.

\section{Part two: subsequent use of tools identified in Sutton et al'}

The literature search identified six papers ${ }^{11,22-26}$ which reported on one or more of the functional decline screening instruments reported by Sutton et al ${ }^{1}$ (HARP was reported in two of the six papers, ${ }^{22,25}$ ISAR in all six,,${ }^{11,22-26}$ SHERPA in one, ${ }^{25}$ and TRST in $\mathrm{two}^{11,26}$ ). No further reports were found on the Inouye instrument. Table 2 lists the assessment items in each screening tool, highlighting the overlap and gaps between these tools.

Braes et $\mathrm{al}^{11}$ conducted a longitudinal comparative study that tested the predictive validity of the TRST and the ISAR. They found the TRST and the ISAR to be comparable regarding their diagnostic characteristics, with a small advantage 


\begin{tabular}{llll}
\hline Predictive validity & Reliability & Generalizability & Clinical utility \\
\hline Discrimination power: & Good reliability between the & Authors validated predictive & Not Reported \\
Developmental cohort: AUC 0.59 & derivation cohort and the validation & indexes in a different region of \\
(range: $0.526-0.635)$ & cohort (good Hosmer-Lemeshow & the country from where it was & developed to test geographic \\
Validation cohort: AUC 0.56 & goodness-of-fit test $(P=0.13))$. & transportability as well as \\
(range: $0.5 \mathrm{I}-0.64 \mathrm{I})$ & Global functional decline rate in the & diagnostic accuracy &
\end{tabular}

\begin{tabular}{|c|c|c|c|}
\hline Predicting IADL deficit cutoff: $3+$ & Not reported & Boyd et $\mathrm{al}^{9}$ indicate BRIGHT & Able to be quickly \\
\hline Sensitivity: 0.76 & & had restricted generalizability & and efficiently \\
\hline Specificity: 0.79 & & at time of publication & administered by \\
\hline AUC 0.83 (95\% Cl: $0.74-0.91)$ & & & nurse. Designed \\
\hline Predicting cognitive performance & & & to be used in \\
\hline Cutoff: $4+$ & & & combination with \\
\hline Sensitivity: 0.70, Specificity: 0.74 & & & the interRAI \\
\hline \multicolumn{4}{|l|}{ AUC 0.73 (95\% Cl: 0.62-0.84) } \\
\hline \multicolumn{4}{|l|}{ Predicting ADLs } \\
\hline \multicolumn{4}{|l|}{ Cutoff: 3 or 4} \\
\hline \multicolumn{4}{|l|}{ Sensitivity: 0.69, Specificity: 0.70} \\
\hline AUC 0.66 (95\% Cl: 0.54-0.78) & & & \\
\hline
\end{tabular}

for the TRST over the ISAR (see Table 3 for psychometric and population data). Based on this, Braes et $\mathrm{al}^{11}$ concluded that both the ISAR and TRST are good screening instruments for functional decline after hospitalization, however, they do add one caveat: the specificity of both tools was low, leading to approximately $50 \%$ false positive scores.

de Saint-Hubert et $\mathrm{al}^{25}$ conducted a prospective cohort study in order to compare the respective performances of the HARP, ISAR, and SHERPA. They found no statistical difference between HARP and ISAR $(P=0.12)$, no significant statistical difference between SHERPA and HARP $(P=0.08)$, but a significant statistical difference between SHERPA and ISAR $(P=0.001)$ (see Table 3 ). They concluded that the SHERPA was the most useful tool for identification of patients at low level risk of functional decline.

Graf et $\mathrm{al}^{26}$ examined a historical cohort to evaluate the performances of ISAR and TRST to predict unplanned readmission after emergency department presentation (see Table 3). The authors concluded that while both tools predicted unplanned hospital readmissions moderately well, they would be better applied to identify patients who could safely be discharged home, and who did not require a more comprehensive geriatric evaluation.

Hoogerduijn et $\mathrm{al}^{22}$ conducted a prospective cohort study comparing the performance of ISAR and HARP (see Table 3).
They concluded that while the instruments tested were strong in both predicting who was at risk of functional decline and who was not at risk, the ISAR showed the best ability to predict functional decline, and was the easier tool to administer.

Salvi et al reported two studies. ${ }^{23,24}$ In $2009,{ }^{23}$ these authors conducted a prospective observational cohort study evaluating the predictive validity of ISAR. With a cutoff of 2 , the ISAR was positive for $70.5 \%$ of patients who had high cognitive impairment, disability, and comorbidities, which was reflected in longer lengths of hospital stay, frailty, and older age. We calculated sensitivity and specificity from raw scores reported in the paper (see Table 3).

In 2012, Salvi et $\mathrm{al}^{24}$ conducted a second prospective observational cohort study to test the validity of the ISAR tool as an indicator of patients in need of a comprehensive geriatric assessment. The authors found that the ISAR was highly correlated with frailty. Using a cutoff score of 3 , they showed ISAR had good sensitivity and specificity (see Table 3), thus allowing for strict selection of frail geriatric patients in an emergency department. The authors concluded that ISAR is a useful screening tool for frailty and identifies those at risk of adverse outcomes after an acute emergency department visit. They also found that the ISAR tool can be used to more effectively select those patients that will benefit from geriatric interventions in the community. 
Table 2 Assessment items reported in the various tools reviewed in this paper

\begin{tabular}{|c|c|c|c|c|c|c|c|}
\hline \multirow{2}{*}{$\begin{array}{l}\text { Functional decline } \\
\text { assessment questions }\end{array}$} & \multicolumn{7}{|c|}{ Functional decline assessment tools } \\
\hline & $\begin{array}{l}\text { BRIGHT } \\
\text { (Boyd } \\
\text { et } \text { al }^{9} \text { ) }\end{array}$ & $\begin{array}{l}\text { HARP } \\
\text { (Sager MA } \\
\left.\text { et } \mathrm{al}^{12}\right)\end{array}$ & $\begin{array}{l}\text { SHERPA } \\
\text { (Cornette } \\
\left.\text { et } \mathrm{al}^{15}\right)\end{array}$ & $\begin{array}{l}\text { ISAR } \\
\text { (McCusker } \\
\left.\text { et } \mathrm{al}^{13}\right)\end{array}$ & $\begin{array}{l}\text { TRST } \\
\text { (Hustey } \\
\text { et } \text { al }^{14} \text { ) }\end{array}$ & $\begin{array}{l}\text { Inouye } \\
\text { instrument } \\
\left(\text { Inouye et } \mathrm{al}^{6}\right)\end{array}$ & $\begin{array}{l}\text { Simplified } \\
\text { PROFUNCTION } \\
\left(\text { Bernabeu-Wittel et } \mathrm{al}^{18} \text { ) }\right.\end{array}$ \\
\hline Age & & $\sqrt{ }$ & $\sqrt{ }$ & & & & $\sqrt{ }$ \\
\hline $\begin{array}{l}\text { Instrumental ADLs } \\
\text { (eight items) }\end{array}$ & $\sqrt{ }$ & $\sqrt{ }$ & $\sqrt{ }$ & & & & \\
\hline Cognitive status (MMSE) & $\sqrt{ }$ & $\sqrt{ }$ & $\sqrt{ }$ & $\sqrt{ }$ & $\sqrt{ }$ & $\sqrt{ }$ & \\
\hline History of hospitalization & & & & $\sqrt{ }$ & $\sqrt{ }$ & & \\
\hline Impaired vision & & & & $\sqrt{ }$ & & & \\
\hline Polypharmacy & & & & $\sqrt{ }$ & $\sqrt{ }$ & & \\
\hline Recent fall & $\sqrt{ }$ & & $\sqrt{ }$ & & $\sqrt{ }$ & & \\
\hline Lives alone & & & & & $\sqrt{ }$ & & \\
\hline Registered nurse concern & & & & & $\sqrt{ }$ & & \\
\hline Decubitus ulcer & & & & & & $\sqrt{ }$ & \\
\hline Social activity level & & & & & & $\sqrt{ }$ & $\sqrt{ }$ \\
\hline Self-rated health & $\sqrt{ }$ & & $\sqrt{ }$ & & & & \\
\hline Basic ADLs (six items) & $\sqrt{ }$ & & & $\sqrt{ }$ & $\sqrt{ }$ & $\sqrt{ }$ & \\
\hline Acute decline in function & & & & $\sqrt{ }$ & & & \\
\hline Feelings of depression & $\sqrt{ }$ & & & & & & \\
\hline Shortness of breath & $\sqrt{ }$ & & & & & & $\sqrt{ }$ \\
\hline Difficulty decision making & $\sqrt{ }$ & & & & & & \\
\hline Bethel index of $>60$ & & & & & & & $\sqrt{ }$ \\
\hline Osteoarticular disease & & & & & & & $\sqrt{ }$ \\
\hline Neurological condition & & & & & & & $\sqrt{ }$ \\
\hline Four polypathology & & & & & & & $\sqrt{ }$ \\
\hline categories & & & & & & & \\
\hline
\end{tabular}

Note: Data for this table was retrieved from the original documents cited in Sutton et al.'

Abbreviations: ADL, activity of daily living; BRIGHT, Brief Risk Identification for Geriatric Health Tool; HARP, Hospital Admission Risk Profile; ISAR, Identification of Seniors At Risk; MMSE, Mini Mental State Examination; SHERPA, Score Hospitalier d'Evaluation du Risque de Perte d'Autonomie; TRST, Triage Risk Screening Tool.

\section{Discussion}

This is the first comprehensive review of functional decline screening tools in 5 years. We have identified that functional decline in elderly patients presenting to an emergency department can now be measured with eight instruments. While not all of the instruments have been tested in an emergency department, their clinical utility and predictive validity suggests that they can appropriately be used in this setting. Since the Sutton et al ${ }^{1}$ review, two new instruments have been developed, which are specific to select patient populations (polypathological older people [Simplified PROFUNCTION], and New Zealand's [BRIGHT]).

Of the five instruments reported in Sutton et al, ${ }^{1}$ six subsequent papers have examined four of the tools. No further research has been conducted on the Inouye tool.

The ISAR instrument is the most commonly reported screening tool since the Sutton review (ie, since 2008). It appears to be the most useful tool for assessing functional decline in elderly patients presenting to an emergency department because it is quick to administer, does not require specialized training for its administrators, and is efficient. It has good predictive capacity in terms of area under the curve and sensitivity (using cut off points at scores of 2 and 3), however specificity is less convincing.

The tools all assess similar constructs, albeit presented in questions using different wording. ADLs are most commonly assessed, although using different ways (validated tools such as Lawton and Brody's instrumental $\mathrm{ADL}^{27}$ and Katz et al's $\mathrm{ADL}^{28}$ ) or using purpose-built questions. The intent of functional decline screening in emergency departments is to gain a snapshot of a patient in a short timeframe, regarding their risk of declining in ADL performance in the next few months. The ability to accurately assess the potential for functional decline in a setting such as an emergency department is an important step in reducing unnecessary hospital readmissions and assisting in maintaining functional independence in the home for older people. In light of this, it is not surprising that the ISAR is the most frequently reported tool, as this is consistently cited as the easiest tool to administer of all those discussed in this paper. 


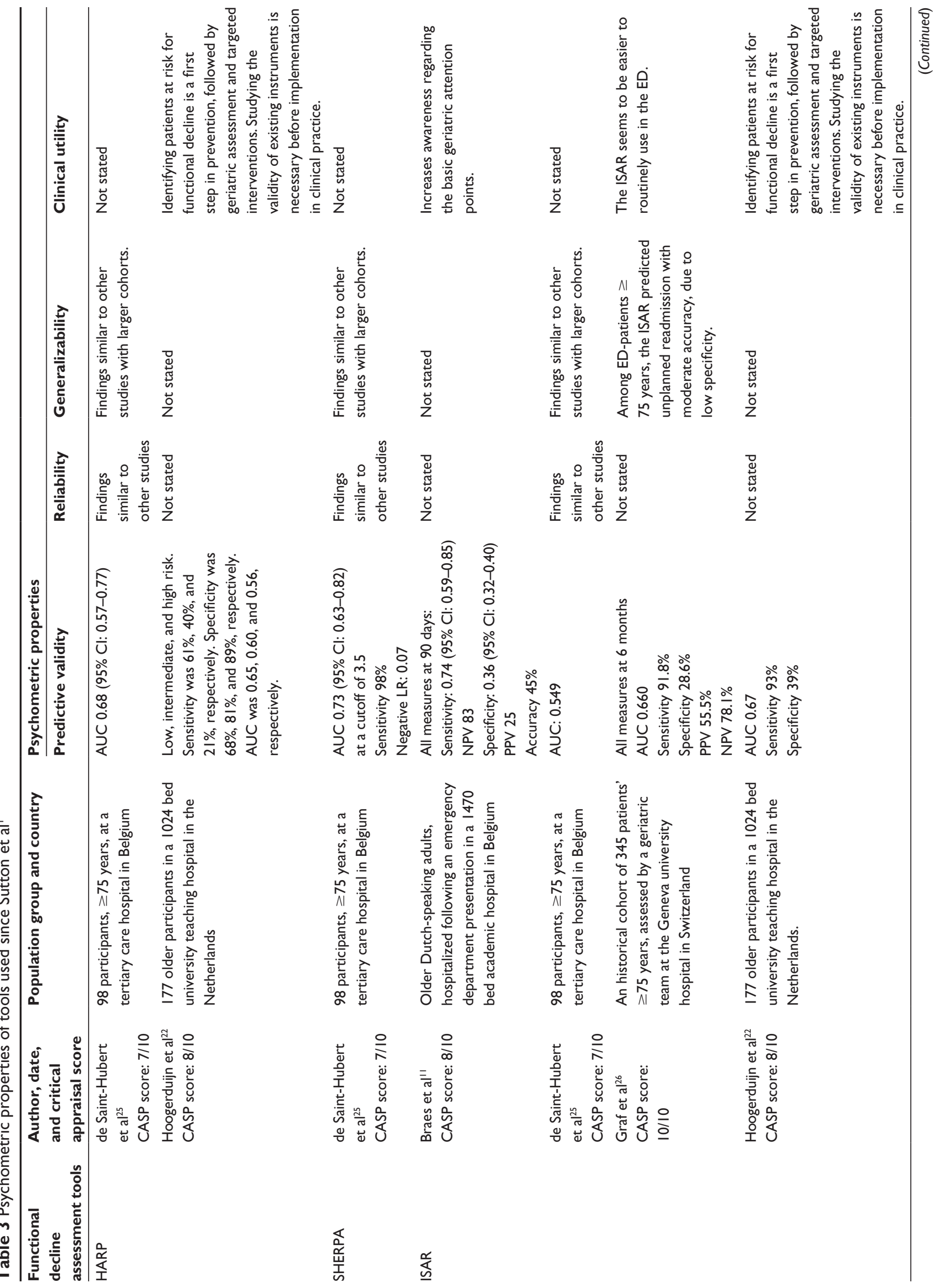




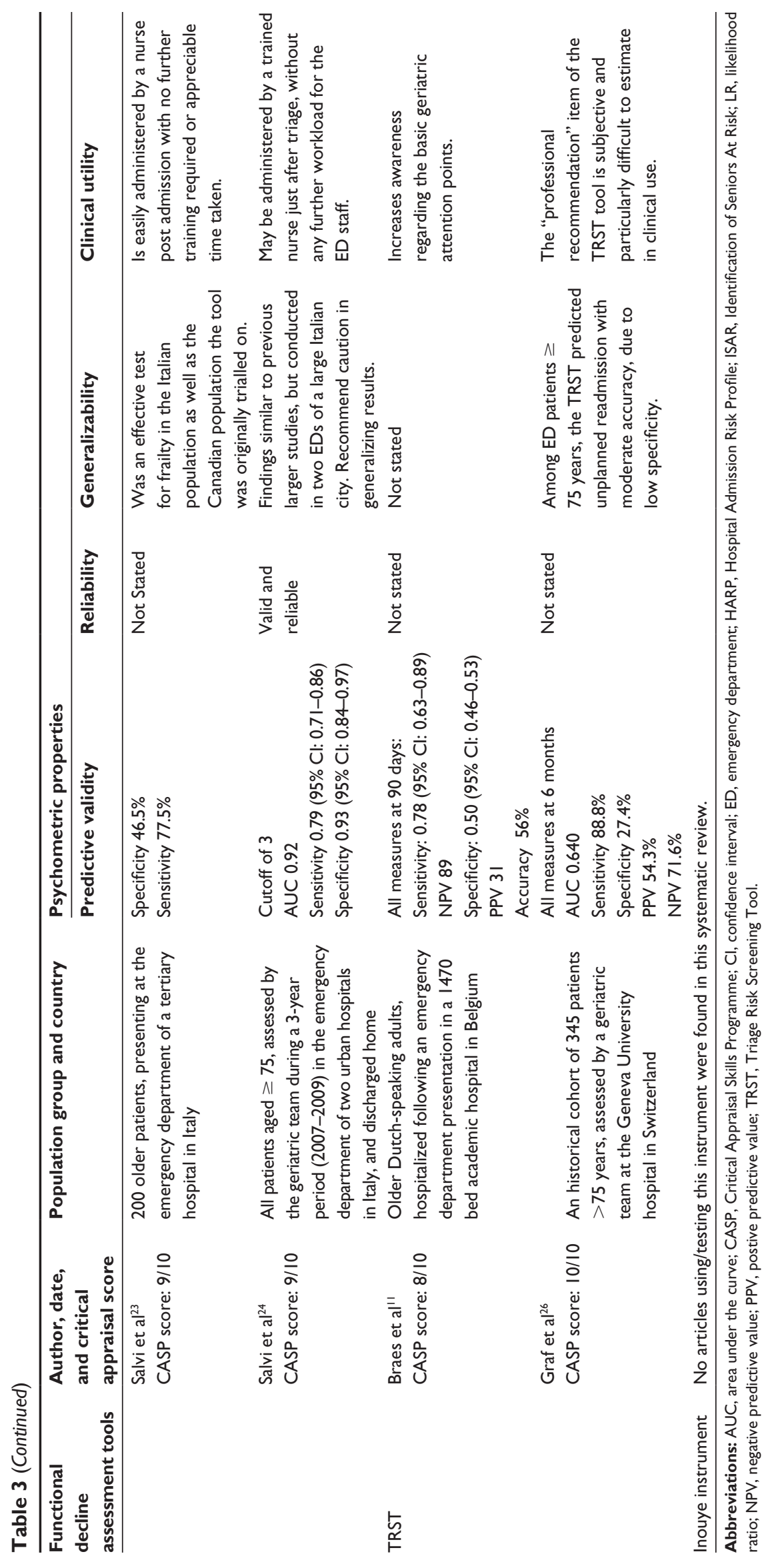


The application of any functional decline screening tool in an emergency department should be carefully considered. Older people presenting to emergency departments are generally sick and distressed, and the emergency department itself is a fast-paced, high-energy environment which may not be conducive to accurate screening. The eight instruments all contained two types of elements: immutable (eg, education, age, living arrangements, and previous mobility state) as well as mutable elements that may well be influenced by the older person's current health state and distress (such as their recollections regarding their ability to manage ADLs, and their cognition). It is probable that poor cognition scores, suspected delirium, poor balance, and depressive feelings, which are often associated with acute illness, ${ }^{12}$ could be abnormally present (ie, not a true reflection of how the older person usually is if they were well). Assessing these elements in a busy emergency department with a sick, distressed individual will affect the accuracy of the assessment. This brings the validity of administration of any functional decline screening tool in an emergency department into question.

However, for many older people, the only time they come to the notice of health professionals is when they are in a health crisis. Therefore, considering them for their capacity to decline functionally over the coming months is essential when the opportunity arises. ${ }^{9,11}$ Thus, a balance needs to be struck between assessing capacity in a less than ideal situation (emergency department) and coming to a wrong conclusion (such as not identifying someone who has the capacity for functional decline, or wrongly identifying someone as having the capacity to decline), compared with not assessing them at all, and allowing functional decline to occur without any attempt at screening. The opportunity for older people to be screened in less stressful environments (such as their doctor's rooms or a community clinic) depends on their regular community health contacts. It would seem that there are opportunities to screen older people more accurately, using any of the tools described in this review, when they are well. However, this requires awareness by community-based health care providers of the need for functional decline assessment as part of aging and regular health checks.

\section{Conclusion}

There are seven documented instruments, with generally similar validity and reliability estimates, to assess older people for functional decline. They contain similar elements and have convincing evidence of applicability to a range of older populations and cultures. To date, the ISAR is the most frequently used, perhaps due to the small number of questions.
However, the bigger issues are how, why, and where any of these functional decline screening tools are used; how valid the findings are on ill, stressed older people in emergency departments; and how the findings are acted upon in terms of community intervention to slow functional decline.

\section{Acknowledgments}

The authors wish to thank Dr Julie Luker for technical aid.

\section{Disclosure}

The authors report no conflicts of interest in this work.

\section{References}

1. Sutton M, Grimmer-Somers K, Jeffries L. Screening tools to identify hospitalised elderly patients at risk of functional decline: a systematic review. Int J Clin Pract. 2008;62(12):1900-1909.

2. Covinsky KE, Justice AC, Rosenthal GE, Palmer RM, Landefeld CS. Measuring prognosis and case mix in hospitalized elders. The importance of functional status. J Gen Intern Med. 1997;12(4):203-208.

3. Mehta KM, Yaffe K, Covinsky KE. Cognitive impairment, depressive symptoms, and functional decline in older people. J Am Geriatr So. 2002;50(6):1045-1050.

4. Covinsky KE, Pierluissi E, Johnston CB. Hospitalization-associated disability: "She was probably able to ambulate, but i'm not sure". JAMA. 2011;306(16):1782-1793.

5. Fortinsky RH, Covinsky KE, Palmer RM, Landefeld CS. Effects of functional status changes before and during hospitalization on nursing home admission of older adults. J Gerontol A Biol Sci Med Sci. 1999; 54(10):M521-M526.

6. Inouye SK, Wagner DR, Acampora D, et al. A predictive index for functional decline in hospitalized elderly medical patients. J Gen Intern Med. 1993;8(12):645-652.

7. Grimmer K, Beaton K, Hendry K, Moss J. Identifying functional decline: a methodological challenge. Patient Relat Outcome Measu. In press. 2013.

8. Brand C, Martin-Khan M, Wright O, et al. Development of quality indicators for monitoring outcomes of frail elderly hospitalised in acute care health settings: study protocol. BMC Health Serv Res. 2011;11:281.

9. Boyd M, Koziol-McLain J, Yates K, et al. Emergency Department casefinding for high-risk older adults: the Brief Risk Identification for Geriatric Health Tool (BRIGHT). Acad Emerg Med. 2008;15(7):598-606.

10. Buurman BM, Hoogerduijn JG, van Gemert EA, de Haan RJ, Schuurmans MJ, de Rooij SE. Clinical characteristics and outcomes of hospitalized older patients with distinct risk profiles for functional decline: a prospective cohort study. PLoS One. 2012;7(1):e29621.

11. Braes T, Flamaing J, Sterckx W, et al. Predicting the risk of functional decline in older patients admitted to the hospital: a comparison of three screening instruments. Age Ageing. 2009;38(5):600-603.

12. Sager MA, Franke T, Inouye SK, et al. Functional outcomes of acute medical illness and hospitalization in older persons. Arch Intern Med. 1996;156(6):645-652.

13. McCusker J, Bellavance F, Cardin S, Trépanier S, Verdon J, Ardman O. Detection of older people at increased risk of adverse health outcomes after an emergency visit: the ISAR screening tool. J Am Geriatr Soc. 1999;47(10):1229-1237.

14. Hustey FM, Mion LC, Connor JT, Emerman CL, Campbell J, Palmer RM. A brief risk stratification tool to predict functional decline in older adults discharged from emergency departments. J Am Geriatr Soc. 2007;55(8):1269-1274.

15. Cornette P, Swine C, Malhomme B, Gillet JB, Meert P, D’Hoore W. Early evaluation of the risk of functional decline following hospitalization of older patients: development of a predictive tool. Eur J Public Health. 2006;16(2):203-208. 
16. Whiting P, Rutjes AW, Reitsma JB, Bossuyt PM, Kleijnen J. The development of QUADAS: a tool for the quality assessment of studies of diagnostic accuracy included in systematic reviews. BMC Med Res Methodol. 2003;3:25.

17. International C. Critical Appraisal Skills Program. Making Sense of Evidence [webpage on the Internet]. Oxford: Critical Appraisal Skills Program; 2012. Available from: http://www.casp-uk.net/wp-content/ uploads/2011/11/CASP_Cohort_Appraisal_Checklist_14oct10.pdf. Accessed Apr 2012.

18. Bernabeu-Wittel M, Ollero-Baturone M, Ruiz-Cantero A, et al. Functional decline over 1-year follow-up in a multicenter cohort of polypathological patients: a new approach to functional prognostication. International Journal of Gerontology. 2012;6(2): 68-74.

19. Carpenter GI, Teare GF, Steel K, et al. A new assessment for elders admitted to acute care: reliability of the MDS-AC. Aging (Milano). 2001;13(4):316-330.

20. Landi F, Tua E, Onder G, et al; SILVERNET-HC Study Group of Bergamo. Minimum data set for home care: a valid instrument to assess frail older people living in the community. Med Care. 2000;38(12): 1184-1190.

21. Hirdes JP, Ljunggren G, Morris JN, et al. Reliability of the interRAI suite of assessment instruments: a 12-country study of an integrated health information system. BMC Health Serv Res. 2008;8:277.
22. Hoogerduijn JG, Schuurmans MJ, Korevaar JC, Buurman BM, de Rooij SE. Identification of older hospitalised patients at risk for functional decline, a study to compare the predictive values of three screening instruments. J Clin Nurs. 2010;19(9-10):1219-1225.

23. Salvi F, Morichi V, Grilli A, et al. Predictive validity of the Identification of Seniors At Risk (ISAR) screening tool in elderly patients presenting to two Italian Emergency Departments. Aging Clin Exp Res. 2009; 21(1):69-75.

24. Salvi F, Morichi V, Grilli A, et al. Screening for frailty in elderly emergency department patients by using the identification of seniors at risk (ISAR). J Nutr Health Aging. 2012;16(4):313-318.

25. de Saint-Hubert M, Jamart J, Boland B, Swine C, Cornette P. Comparison of three tools predicting functional decline after hospitalization of older patients. J Am Geriatr Soc. 2010;58(5):1003-1005.

26. Graf CE, Giannelli SV, Herrmann FR, et al. Identification of older patients at risk of unplanned readmission after discharge from the emergency department - comparison of two screening tools. Swiss Med Wkly. 2012;141:w13327.

27. Lawton M, Brody E. Assessment of older people: self-maintaining and instrumental activities of daily living. Gerontologist. 1969;9(3): 179-186.

28. Katz S, Ford AB, Moskowitz RW, Jackson BA, Jaffe MW. Studies of illness in the aged: The index of ADL: a standardized measure of biological and psychosocial function. JAMA. 1963;185:914-919.
Clinical Interventions in Aging

\section{Publish your work in this journal}

Clinical Interventions in Aging is an international, peer-reviewed journal focusing on evidence-based reports on the value or lack thereof of treatments intended to prevent or delay the onset of maladaptive correlates of aging in human beings. This journal is indexed on PubMed Central, MedLine, the American Chemical Society's 'Chemical Abstracts

\section{Dovepress}

Service' (CAS), Scopus and the Elsevier Bibliographic databases. The manuscript management system is completely online and includes a very quick and fair peer-review system, which is all easy to use. Visit $\mathrm{http}: / /$ www.dovepress.com/testimonials.php to read real quotes from published authors. 